\title{
FLUORESCENCE OF POLARIZED ATOMS IONIZED BY POLARIZED ELECTRONS
}

\author{
A. Kupliauskiené ${ }^{\mathrm{a}}$, K. Glemža ${ }^{\mathrm{b}}$, and K.-N. Huang ${ }^{\mathrm{c}}$ \\ a Institute of Theoretical Physics and Astronomy of Vilnius University, A. Goštauto 12, LT-01108 Vilnius, Lithuania \\ E-mail: akupl@itpa.lt \\ ${ }^{\mathrm{b}}$ Faculty of Physics, Vilnius University, Sauletekio 9, LT-10222 Vilnius, Lithuania \\ E-mail: kazimieras.glemza@ff.vu.lt \\ ${ }^{\mathrm{c}}$ Institute of Atomic and Molecular Sciences, Academia Sinica, P.O. Box 23-166, Taipei, Taiwan 106, Republic of China \\ E-mail: knhuang@sinica.edu.tw
}

Received 19 November 2007; accepted 22 February 2008

\begin{abstract}
A general expression for the differential cross-section describing the properties of radiation following the ionization of polarized atoms by polarized electrons is obtained in two-step approximation by using the methods of atomic theory. The special cases of the general expression suitable for the specific experiments are derived. In the case of the ionization of nonpolarized atoms by non-polarized electrons, the expressions for the parameters of the asymmetry in the angular distribution of fluorescence as well as angular correlations between fluorescence photon and one of emitted electrons are presented. The magnetic dichroism in the angular distribution of fluorescence radiation is studied.
\end{abstract}

Keywords: ionization of atoms by electron impact, polarization, angular distribution, fluorescence

PACS: $31.10 .+\mathrm{z}, 34.80 . \mathrm{Dp}, 34.80 . \mathrm{Nz}, 32.50 .+\mathrm{d}$

\section{Introduction}

The ionization of atoms by electrons is one the most important processes in plasmas. Polarized atoms and ions are present in plasma where directed flow of charged particles take place. Then, the emitted radiation can also be polarized [1]. The tokamak may serve as an example of such devices. The polarization of electron-impact excited radiation or fluorescence from tokamak plasmas was used for its diagnostics $[2,3]$. This polarization is caused by non-equilibrium population of magnetic levels or ordering of the excited and ionized atoms, otherwise known as self-alignment. It arises in the collision process because of oriented flow of atoms or (and) electrons [1]. Thus, for theoretical modelling of elementary processes in plasmas, the expressions of the cross-sections describing the polarization of atoms both in initial and final states are of importance. The main task of the present work was the derivation of a general expression for the cross-section suitable to describe the properties of fluorescence radiation following ionization of polarized atoms by polarized electrons.

Density matrix formalism [4] was the usual method for investigation of polarization and angular distributions in these processes for many years. Recently, a number of alternative methods was introduced [511]. A unified quantum collision theory in the wavepacket approach for the analysis of kinematics of various atomic collision processes by using the density matrix, relativistic approach, and helicity formulations was proposed by Huang [5]. Da Pieve et al. [6] have commenced studying the angular correlation between a photoelectron and subsequent Auger electron from atomic targets in a single particle scattering approach, since it is more convenient for extension to the solid state case. The methods usually used in atomic theory were applied for the investigation of photoionization of polarized atoms by Kupliauskienè et al. [7,8]. In this approach, the probability or cross-section of the interaction of polarized electrons (photons) with polarized atoms was expressed as a multiple expansion over the multipoles (irreducible tensors) of the state of all particles taking part in the process both in initial and final states [7-10]. The extension of this method to the multistep processes was presented in [11]. The ionization of polarized atoms by polarized electrons was investigated 
by Kupliauskienė and Glemža [9] using distorted wave approximation as well.

The investigations of fluorescence following ionization of atoms by electrons are not numerous. In the case of ionization of non-polarized atoms by non-polarized electrons, the expressions for angular distribution of Auger electrons were obtained by Berezhko et al. [12] using the density matrix approach. Recently, the asymmetry of angular distribution and polarization of argon $\mathrm{KX}$-radiation following the ionization of non-polarized atoms by non-polarized electrons was investigated ex- perimentally [13]. Thus, the present work is a further development of atomic theory methods for twostep process of fluorescence following the ionization of atoms by electrons. The next section is devoted to obtaining the general expression by applying a method used in atomic theory. Its special cases are presented in Section 3. The inequality 'fine structure splitting $\gg$ line width $\gg$ hyperfine structure splitting' is also assumed. Modifications enabling one to take into account hyperfine structure splitting can be easily made $[8,10]$.

\section{General expression}

The process of the fluorescence radiation following ionization of polarized atoms by polarized electrons can be written as follows:

$$
\begin{aligned}
& A\left(\alpha_{1} J_{1} M_{1}\right)+e^{-}\left(\mathbf{p}_{0} m_{0}\right) \rightarrow A^{+}\left(\alpha_{2} J_{2} M_{2}\right)+e^{-}\left(\mathbf{p}_{2} m_{2}\right)+e^{-}\left(\mathbf{p}_{1} m_{1}\right) \\
& \rightarrow A^{+}\left(\alpha_{3} J_{3} M_{3}\right)+e^{-}\left(\mathbf{p}_{2} m_{2}\right)+e^{-}\left(\mathbf{p}_{1} m_{1}\right)+h \nu\left(\hat{\epsilon}_{q} \mathbf{k}_{0}\right) .
\end{aligned}
$$

Here $\alpha_{i}$ indicates the configuration and other quantum numbers, $J_{i}$ is the quantum number of the total angular momentum, and $M_{i}$ is its projection onto a chosen direction for atoms (ions) in the initial $(i=1)$, intermediate $(i=2)$, and final $(i=3)$ states, respectively, $\mathbf{p}_{i}, m_{i}$ are the momentum of an electron and its spin projection in the initial $(i=0)$ and final $(i=1,2)$ states. The energy $\varepsilon$ (in atomic units) of an electron is related to its momentum $p$ via $p=(2 \varepsilon)^{1 / 2} \cdot \mathbf{k}_{0}$ indicates the wave vector of emitted photon, and $\hat{\epsilon}_{q}$ is its polarization unit vector, where $q= \pm 1$ for circularly polarized light. Any other polarization can be obtained as a superposition of left- and right-hand polarizations.

In two-step approximation, the expression of fourfold differential cross-section, describing fluorescence decay following the ionization of polarized atoms by polarized electrons, can be written in the form of an expansion over the multipoles of a non-registered intermediate state of ion $A^{+}\left(\alpha_{2} J_{2} M_{2}\right)$ by using the method proposed in [11] as follows:

$$
\begin{aligned}
& \frac{\mathrm{d}^{4} \sigma\left(\alpha_{1} J_{1} M_{1} \mathbf{p}_{0} m_{0} \rightarrow \alpha_{2} J_{2} \mathbf{p}_{1} m_{1} \mathbf{p}_{2} m_{2} \rightarrow \alpha_{3} J_{3} M_{3} \hat{\epsilon}_{q} \mathbf{k}_{0}\right)}{\mathrm{d} \varepsilon_{2} \mathrm{~d} \Omega_{1} \mathrm{~d} \Omega_{2} \mathrm{~d} \Omega_{k 0}}= \\
& \sum_{K_{2} N_{2}} \frac{\mathrm{d}^{3} \sigma_{K_{2} N_{2}}^{\text {ion }}\left(\alpha_{1} J_{1} M_{1} \mathbf{p}_{0} m_{0} \rightarrow \alpha_{2} J_{2} \mathbf{p}_{1} m_{1} \mathbf{p}_{2} m_{2}\right)}{\mathrm{d} \varepsilon_{2} \mathrm{~d} \Omega_{1} \mathrm{~d} \Omega_{2}} \frac{\mathrm{d} W_{K_{2} N_{2}}^{r}\left(\alpha_{2} J_{2} \rightarrow \alpha_{3} J_{3} M_{3} \hat{\epsilon}_{q} \mathbf{k}_{0}\right)}{\mathrm{d} \Omega_{k_{0}}} .
\end{aligned}
$$

In (2), $\mathrm{d} \Omega_{i}$ describe the scattering angle for the scattered $(i=1)$ and emitted $(i=2)$ electrons and fluorescence photons $\left(i=k_{0}\right)$.

The expression for the first term in (2) can be obtained from Eq. (13) of [9] by applying the procedure described in $[10,11]$ and it is as follows:

$$
\begin{aligned}
& \frac{\mathrm{d}^{3} \sigma_{K_{2} N_{2}}^{\text {ion }}\left(\alpha_{1} J_{1} M_{1} \mathbf{p}_{0} m_{0} \rightarrow \alpha_{2} J_{2} \mathbf{p}_{2} m_{2} \mathbf{p}_{1} m_{1}\right)}{\mathrm{d} \varepsilon_{2} \mathrm{~d} \Omega_{1} \mathrm{~d} \Omega_{2}}=C_{2}(4 \pi)^{3 / 2}\left[2 K_{2}+1\right]^{1 / 2} \\
& \times \sum_{\substack{K, K_{0}, K_{0}^{\prime}, K_{\lambda 0}, K_{s 0}, K^{\prime}, K_{1}^{\prime}, K_{2}^{\prime}, K_{\lambda 1}, K_{s 1}, K_{\lambda 2}, K_{s 2}}}^{\mathcal{B}^{\text {ion }}\left(K_{0}, K_{0}^{\prime}, K, K_{\lambda 0}, K_{s 0}, K_{2}, K^{\prime}, K_{\lambda 1}, K_{s 1}, K_{1}^{\prime}, K_{\lambda 2}, K_{s 2}, K_{2}^{\prime}\right)}
\end{aligned}
$$




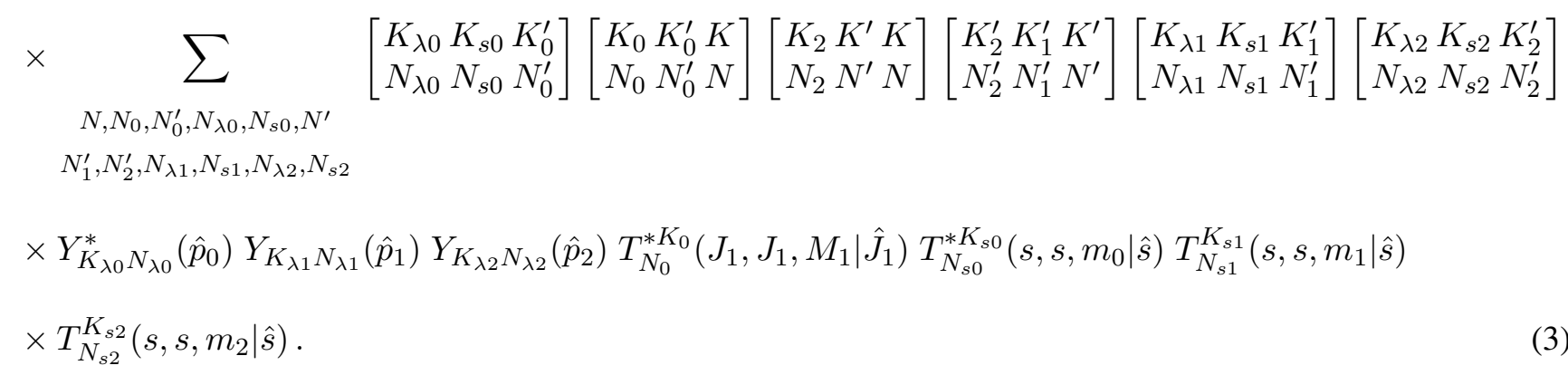

Here

$$
C_{2}=\frac{2 p_{1} p_{2}}{\pi^{2} p_{0}}, \quad T_{N}^{K}(J, J, M \mid \hat{J})=(-1)^{J-M}\left[\frac{4 \pi}{2 J+1}\right]^{1 / 2}\left[\begin{array}{ccc}
J & J & K \\
M & -M & 0
\end{array}\right] Y_{K N}(\hat{J})
$$

where $\hat{J}$ denotes the polar and azimuthal angles of the orientation of the angular momentum $\mathbf{J}$ with respect to the chosen $z$ axis, and

$$
\begin{aligned}
& \mathcal{B}^{\text {ion }}\left(K_{0}, K_{0}^{\prime}, K, K_{\lambda 0}, K_{s 0}, K_{2}, K^{\prime}, K_{\lambda 1}, K_{s 1}, K_{1}^{\prime}, K_{\lambda 2}, K_{s 2}, K_{2}^{\prime}\right)= \\
& \sum(2 J+1)\left(2 J^{\prime}+1\right)(2 s+1)(-1)^{\lambda_{0}^{\prime}+\lambda_{1}^{\prime}+\lambda_{2}^{\prime}}\left[\begin{array}{ccc}
\lambda_{0} & \lambda_{0}^{\prime} & K_{\lambda 0} \\
0 & 0 & 0
\end{array}\right]\left[\begin{array}{ccc}
\lambda_{1} & \lambda_{1}^{\prime} & K_{\lambda 1} \\
0 & 0 & 0
\end{array}\right]\left[\begin{array}{ccc}
\lambda_{2} & \lambda_{2}^{\prime} & K_{\lambda 2} \\
0 & 0 & 0
\end{array}\right] \\
& \lambda_{0}, \lambda_{0}^{\prime}, \lambda_{1}, \lambda_{1}^{\prime}, \lambda_{2}, \lambda_{2}^{\prime}, j_{0}, j_{0}^{\prime} \\
& j_{1}, j_{1}^{\prime}, j_{2}, j_{2}^{\prime}, J, J^{\prime}, j, j^{\prime} \\
& \times\left\langle\alpha_{2} J_{2}, \varepsilon_{2} \lambda_{2}\left(j_{2}\right) \varepsilon_{1} \lambda_{1}\left(j_{1}\right) j, J\|V\| \alpha_{1} J_{1}, \varepsilon_{0} \lambda_{0}\left(j_{0}\right) J\right\rangle\left\langle\alpha_{2} J_{2}, \varepsilon_{2} \lambda_{2}^{\prime}\left(j_{2}^{\prime}\right) \varepsilon_{1} \lambda_{1}^{\prime}\left(j_{1}^{\prime}\right) j^{\prime}, J^{\prime}\|V\| \alpha_{1} J_{1}, \varepsilon_{0} \lambda_{0}^{\prime}\left(j_{0}^{\prime}\right) J^{\prime}\right\rangle^{*} \\
& \times\left[(2 s+1)\left(2 \lambda_{0}+1\right)\left(2 \lambda_{0}^{\prime}+1\right)\left(2 \lambda_{1}+1\right)\left(2 \lambda_{1}^{\prime}+1\right)\left(2 \lambda_{2}+1\right)\left(2 \lambda_{2}^{\prime}+1\right)\left(2 j_{0}+1\right)\left(2 j_{0}^{\prime}+1\right)\left(2 j_{1}+1\right)\left(2 j_{1}^{\prime}+1\right)\right. \\
& \left.\times\left(2 j_{2}+1\right)\left(2 j_{2}^{\prime}+1\right)(2 j+1)\left(2 j^{\prime}+1\right)\left(2 J_{1}+1\right)\left(2 J_{2}+1\right)\left(2 K_{0}^{\prime}+1\right)\left(2 K_{1}^{\prime}+1\right)\left(2 K^{\prime}+1\right)\left(2 K_{2}^{\prime}+1\right)\right]^{1 / 2}
\end{aligned}
$$

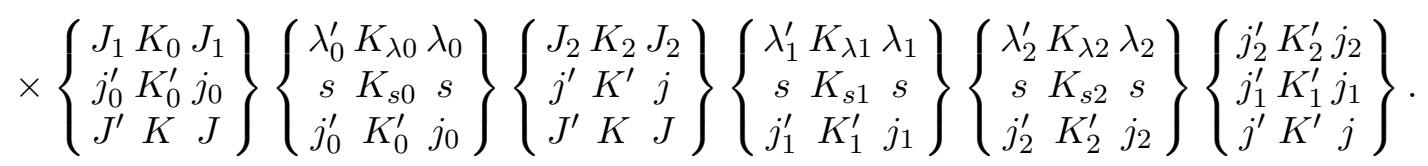

In (5), $V$ in the reduced matrix element [9] marks the operator of electrostatic interaction between atomic and projectile or scattered and emitted electrons.

The second term in (2) has the following expression $[10,14]$ :

$$
\begin{aligned}
& \frac{\mathrm{d} W_{K_{2} N_{2}}^{r}\left(\alpha_{2} J_{2} \rightarrow \alpha_{3} J_{3} M_{3} \hat{\epsilon}_{q} \mathbf{k}_{0}\right)}{\mathrm{d} \Omega_{k_{0}}}= \\
& C_{1} \sum_{K_{r}^{\prime}, K_{3}, k, k^{\prime}} \mathcal{A}\left(K_{2}, K_{r}^{\prime}, K_{3}, k, k^{\prime}\right) \\
& \times \sum_{N_{r}^{\prime}, N_{3}}\left[\begin{array}{lll}
K_{2} & K_{r}^{\prime} & K_{3} \\
N_{2} & N_{r}^{\prime} & N_{3}
\end{array}\right] T_{N_{3}}^{K_{3}}\left(J_{3}, J_{3}, M_{3} \mid \hat{J}_{3}\right) \\
& \times T_{N_{r}^{\prime}}^{K_{r}^{\prime}}\left(k, k^{\prime}, q \mid \hat{\mathbf{k}}_{0}\right),
\end{aligned}
$$

$$
\begin{aligned}
& \mathcal{A}\left(K_{2}, K_{r}^{\prime}, K_{3}, k, k^{\prime}\right)= \\
& \times\left(\alpha_{3} J_{3}\left\|Q^{(k)}\right\| \alpha_{2} J_{2}\right)\left(\alpha_{3} J_{3}\left\|Q^{\left(k^{\prime}\right)}\right\| \alpha_{2} J_{2}\right)^{*} \\
& \times\left[\frac{\left(2 K_{2}+1\right)\left(2 J_{3}+1\right)(2 k+1)}{\left(2 J_{2}+1\right)\left(2 K_{3}+1\right)}\right]^{1 / 2}\left\{\begin{array}{lll}
J_{2} & K_{2} & J_{2} \\
k & K_{r}^{\prime} & k^{\prime} \\
J_{3} & K_{3} & J_{3}
\end{array}\right\} .
\end{aligned}
$$

The reduced matrix element in (7) is equal to

$$
\left(\alpha_{3} J_{3}\left\|Q^{(k)}\right\| \alpha_{2} J_{2}\right)=\sqrt{2 J_{3}+1}\left\langle\alpha_{3} J_{3}\left\|Q^{(k)}\right\| \alpha_{2} J_{2}\right\rangle,
$$

the constant $C_{1}=1 /(2 \pi)$, and

$$
\left\langle\alpha_{3} J_{3}\left\|Q^{(k)}\right\| \alpha_{2} J_{2}\right\rangle=k_{0}^{k+1 / 2} \sum_{p=0,1}\left[\frac{k+1}{k}\right]^{1 / 2}
$$




$$
\times \frac{\mathrm{i}^{k}(-\mathrm{i} q)^{p}}{(2 k-1) ! !}\left\langle\alpha_{3} J_{3}\left\|\mathcal{Q}_{k}^{p}\right\| \alpha_{2} J_{2}\right\rangle
$$

is defined in [10]. $p=0$ indicates the operator of electric multipole transition $(\mathrm{E} k)$ [15]

$$
\mathcal{Q}_{k q}^{0}=-r^{k} C_{q}^{(k)},
$$

and $p=1$ represents the operator of magnetic multipole transition $(\mathrm{M} k)$ [15]

$$
\begin{aligned}
& \mathcal{Q}_{k q}^{1}=-\frac{1}{c}[k(2 k-1)]^{1 / 2} r^{k-1} \\
& \times\left\{\frac{1}{k+1}\left[C^{(k-1)} \times L^{(1)}\right]_{q}^{(k)}+\left[C^{(k-1)} \times S^{(1)}\right]_{q}^{(k)}\right\} .
\end{aligned}
$$

Here $L^{(1)}$ and $S^{(1)}$ are operators of orbital and spin angular momentum, respectively, $C_{q}^{(k)}$ is operator of spherical function normalized to $[4 \pi /(2 k+1)]^{1 / 2}[16]$.

Note that the parities of electric and magnetic multipole fields are $(-1)^{k}$ and $(-1)^{k+1}$, respectively. Only either magnetic $(\mathrm{M} k)$ or electric $(\mathrm{E} k)$ part contributes between specific electronic states, owing to parity selection rules. Since we are considering pure photon states,

there is no need to introduce Stokes parameters explicitly.

The expressions (2), (3), and (6) represent the most general case of the cross-section describing the polarization of all particles participating in the process (1) and angular distributions as well as angular correlations of the electrons and photon in the final state. These general expressions can be used to derive the expressions applicable for specific experimental conditions with smaller number of polarization states specified. To obtain the special cases, one needs to integrate over the angles of one or both escaping electrons and to sum over the magnetic components of some angular momenta. The following summation and integration formulae [8] make this easier:

$$
\sum_{M} T_{N}^{K}(J, J, M \mid \hat{J})=\delta(K, 0) \delta(N, 0),
$$

$$
\int_{0}^{\pi} \int_{0}^{2 \pi} Y_{K N}(\theta, \phi) \sin \theta \mathrm{d} \theta \mathrm{d} \phi=\sqrt{4 \pi} \delta(K, 0) \delta(N, 0) .
$$

Usually, the experiments are performed by using both non-polarized atoms and non-polarized electrons and the state of polarization of the scattered and emitted electrons as well as that of ion in the final state are not registered. Then, expressions (3) and (6) become simpler because of $K_{0}=K_{s 0}=K_{s 1}=K_{s 2}=0, K_{\lambda_{0}}=K_{0}^{\prime}=K$, $K_{\lambda_{1}}=K_{1}^{\prime}, K_{\lambda_{2}}=K_{2}^{\prime}$ :

$$
\begin{aligned}
& \frac{\mathrm{d}^{3} \sigma_{K_{2} N_{2}}^{\text {ion }}\left(\alpha_{1} J_{1} \mathbf{p}_{0} \rightarrow \alpha_{2} J_{2} \mathbf{p}_{2} \mathbf{p}_{1}\right)}{\mathrm{d} \varepsilon_{2} \mathrm{~d} \Omega_{1} \mathrm{~d} \Omega_{2}}= \\
& \frac{C_{2}(4 \pi)^{3 / 2}\left[2 K_{2}+1\right]^{1 / 2}}{2\left(2 J_{1}+1\right)} \sum_{K_{\lambda_{0}}, K^{\prime}, K_{\lambda_{1}}, K_{\lambda_{2}}} \mathcal{B}^{\text {ion }}\left(0, K_{\lambda_{0}}, K_{\lambda_{0}}, K_{\lambda_{0}}, 0, K_{2}, K^{\prime}, K_{\lambda_{1}}, 0, K_{\lambda_{1}}, K_{\lambda_{2}}, 0, K_{\lambda_{2}}\right) \\
& \times \sum_{N_{\lambda_{0}}, N^{\prime}, N_{\lambda_{1}}, N_{\lambda_{2}}}\left[\begin{array}{l}
K_{2} K^{\prime} K_{\lambda_{0}} \\
N_{2} N^{\prime} N_{\lambda_{0}}
\end{array}\right]\left[\begin{array}{l}
K_{\lambda_{2}} K_{\lambda_{1}} K^{\prime} \\
N_{\lambda_{2}} N_{\lambda_{1}} N^{\prime}
\end{array}\right] Y_{K_{\lambda_{0}} N_{\lambda_{0}}}^{*}\left(\hat{p}_{0}\right) Y_{K_{\lambda_{1}} N_{\lambda_{1}}}\left(\hat{p}_{1}\right) Y_{K_{\lambda_{2}} N_{\lambda_{2}}}\left(\hat{p}_{2}\right), \\
& \frac{\mathrm{d} W_{K_{2} N_{2}}^{r}\left(\alpha_{2} J_{2} \rightarrow \alpha_{3} J_{3} \hat{\epsilon}_{q} \mathbf{k}_{0}\right)}{\mathrm{d} \Omega_{k 0}}= \\
& \frac{1}{2 \pi\left(2 J_{2}+1\right)} \sum_{k, k^{\prime}}\left[\frac{4 \pi}{(2 k+1)\left(2 K_{2}+1\right)}\right]^{1 / 2}(-1)^{K_{2}-N_{2}+k^{\prime}-q}\left[\begin{array}{ccc}
k & k^{\prime} & K_{2} \\
q-q & 0
\end{array}\right] \mathcal{A}\left(K_{2}, K_{2}, 0, k, k^{\prime}\right) Y_{K_{2}-N_{2}}\left(\hat{k}_{0}\right) .
\end{aligned}
$$

In the case of $N_{2}=0$, we have

$$
\frac{\mathrm{d} W_{K_{2} 0}^{r}\left(\alpha_{2} J_{2} \rightarrow \alpha_{3} J_{3} \hat{\epsilon}_{q} \mathbf{k}_{0}\right)}{\mathrm{d} \Omega_{k 0}}=
$$




$$
\frac{1}{2 \pi\left(2 J_{2}+1\right)} \sum_{k, k^{\prime}}(-1)^{K_{2}+k^{\prime}-q}\left[\frac{1}{2 k+1}\right]^{1 / 2}\left[\begin{array}{ccc}
k & k^{\prime} & K_{2} \\
q-q & 0
\end{array}\right] \mathcal{A}\left(K_{2}, K_{2}, 0, k, k^{\prime}\right) P_{K_{2}}\left(\cos \theta_{k_{0}}\right),
$$

where $P_{K_{2}}\left(\cos \theta_{k_{0}}\right)$ is Legendre polynomial.

Some more simple cases of the general expression (2) are derived further as examples. They cover the most frequently measured set of characteristics and use the experiment geometry. Expressions (14) and (15) enable one to readily obtain a number of special cases.

\section{Special cases}

\subsection{Total cross-section for fluorescence following the ionization of non-polarized atoms by non-polarized electrons.}

The total cross-section describing the fluorescence radiation emitted after ionization of non-polarized atoms by non-polarized electrons, when the polarization state of particles in the final stage of the process (1) are not registered, can be obtained from the general expression (2) by summing over the magnetic components of particles in the final state and averaging over them in the initial state, as well as integration over the angles of scattered and emitted electrons and radiation. The result of these procedures can be written as a product of two probabilities:

$$
\begin{aligned}
& \sigma\left(\alpha_{1} J_{1} \rightarrow \alpha_{2} J_{2} \rightarrow \alpha_{3} J_{3}\right)=\frac{1}{2\left(2 J_{1}+1\right)} \\
& \times \int \mathrm{d} \varepsilon_{2} \int \mathrm{d} \Omega_{1} \int \mathrm{d} \Omega_{2} \int \mathrm{d} \Omega_{k_{0}} \sum_{M_{1}, M_{3}, m_{0}, m_{1}, m_{2}} \frac{\mathrm{d}^{4} \sigma\left(\alpha_{1} J_{1} M_{1} \mathbf{p}_{0} m_{0} \rightarrow \alpha_{2} J_{2} \mathbf{p}_{1} m_{1} \mathbf{p}_{2} m_{2} \rightarrow \alpha_{3} J_{3} M_{3} \hat{\epsilon}_{q} \mathbf{k}_{0}\right)}{\mathrm{d} \varepsilon_{2} \mathrm{~d} \Omega_{1} \mathrm{~d} \Omega_{2} \mathrm{~d} \Omega_{k 0}}= \\
& =\sigma^{\text {ion }}\left(\alpha_{1} J_{1} \rightarrow \alpha_{2} J_{2}\right) W^{r}\left(\alpha_{2} J_{2} \rightarrow \alpha_{3} J_{3}\right) .
\end{aligned}
$$

On the right-hand side of (17), the first term is the total ionization cross-section of an atom, and the second term is the probability of radiative transition between the levels in ion $A^{+}$.

\subsection{Angular distribution of fluorescence radiation following the ionization of non-polarized atoms by non-polarized electrons}

The cross-section describing the asymmetry of angular distribution of fluorescence radiation following the ionization of non-polarized atoms by non-polarized electrons can be obtained from the general expression (2) by summing over the magnetic components of particles in the final state and averaging over them in the initial state, as well as integration over the angles of scattered and emitted electrons. But a simpler way is to use the expressions (14) and (15). Then the differential cross-section for the asymmetry of angular distribution of the fluorescence radiation is as follows:

$$
\begin{aligned}
& \frac{\mathrm{d} \sigma\left(\alpha_{1} J_{1} \mathbf{p}_{0} \rightarrow \alpha_{2} J_{2} \rightarrow \alpha_{3} J_{3} \hat{\epsilon}_{q} \mathbf{k}_{0}\right)}{\mathrm{d} \Omega_{k_{0}}}= \\
& \frac{1}{2\left(2 J_{1}+1\right)} \int \mathrm{d} \varepsilon_{2} \int \mathrm{d} \Omega_{1} \int \mathrm{d} \Omega_{2} \sum_{M_{1}, M_{3}, m_{0}, m_{1}, m_{2}} \frac{\mathrm{d}^{4} \sigma\left(\alpha_{1} J_{1} M_{1} \mathbf{p}_{0} m_{0} \rightarrow \alpha_{2} J_{2} \mathbf{p}_{1} m_{1} \mathbf{p}_{2} m_{2} \rightarrow \alpha_{3} J_{3} M_{3} \hat{\epsilon}_{q} \mathbf{k}_{0}\right)}{\mathrm{d} \varepsilon_{2} \mathrm{~d} \Omega_{1} \mathrm{~d} \Omega_{2} \mathrm{~d} \Omega_{k 0}}= \\
& \sum_{K_{2}, N_{2}} \sigma_{K_{2} N_{2}}^{\text {ion }}\left(\alpha_{1} J_{1} \mathbf{p}_{0} \rightarrow \alpha_{2} J_{2}\right) \frac{\mathrm{d} W_{K_{2} N_{2}}^{r}\left(\alpha_{2} J_{2} \rightarrow \alpha_{3} J_{3} \hat{\epsilon}_{q} \mathbf{k}_{0}\right)}{\mathrm{d} \Omega_{k_{0}}} .
\end{aligned}
$$


Here

$$
\sigma_{K_{2} N_{2}}^{\text {ion }}\left(\alpha_{1} J_{1} \mathbf{p}_{0} \rightarrow \alpha_{2} J_{2}\right)=(4 \pi)^{2} \frac{C_{2}\left[4 \pi\left(2 K_{2}+1\right)\right]^{1 / 2}}{2\left(2 J_{1}+1\right)} Y_{K_{2} N_{2}}^{*}\left(\hat{p}_{0}\right) \mathcal{B}^{\text {ion }}\left(0, K_{2}, K_{2}, K_{2}, 0, K_{2}, 0,0,0,0,0,0,0\right),
$$

and the expression for the second term is (15). The choice of laboratory $z$ axis along the direction of incoming electrons leads to $Y_{K_{2}, N_{2}}^{*}(0,0)=\left[\left(2 K_{2}+1\right) / 4 \pi\right]^{1 / 2} \delta\left(N_{2}, 0\right)$, and then

$$
\sigma_{K_{2} 0}^{\text {ion }}\left(\alpha_{1} J_{1} \rightarrow \alpha_{2} J_{2}\right)=(4 \pi)^{2} \frac{C_{2}\left(2 K_{2}+1\right)}{2\left(2 J_{1}+1\right)} \mathcal{B}^{\text {ion }}\left(0, K_{2}, K_{2}, K_{2}, 0, K_{2}, 0,0,0,0,0,0,0\right) .
$$

Then the expression for the cross-section describing the angular distribution of fluorescence radiation following the ionization of non-polarized atoms by non-polarized electrons can be written in the following form:

$$
\frac{\mathrm{d} \sigma\left(\alpha_{1} J_{1} \rightarrow \alpha_{2} J_{2} \rightarrow \alpha_{3} J_{3} \mathbf{k}_{0}\right)}{\mathrm{d} \Omega_{k_{0}}}=\frac{\sigma^{\mathrm{ion}}\left(\alpha_{1} J_{1} \rightarrow \alpha_{2} J_{2}\right)}{(4 \pi)^{2}} \frac{W^{r}\left(\alpha_{2} J_{2} \rightarrow \alpha_{3} J_{3}\right)}{4 \pi}\left[1+\sum_{K_{2}} \beta_{K_{2}} P_{K_{2}}(\cos \theta)\right],
$$

where

$$
\beta_{K_{2}}=\alpha_{K_{2}} A_{K_{2}}
$$

Here

$$
A_{K_{2}}=\frac{\left(2 K_{2}+1\right) \int \mathrm{d} \varepsilon_{2} \mathcal{B}^{\text {ion }}\left(0, K_{2}, K_{2}, K_{2}, 0, K_{2}, 0,0,0,0,0,0,0\right)}{\int \mathrm{d} \varepsilon_{2} \mathcal{B}^{\text {ion }}(0,0,0,0,0,0,0,0,0,0,0,0,0)}
$$

is the alignment of a non-polarized atom ionized by non-polarized electrons, and

$$
\alpha_{K_{2}}=\frac{\sum_{k, k^{\prime}}(-1)^{K_{2}+k^{\prime}-q}\left[\frac{1}{2 k^{\prime}+1}\right]^{1 / 2}\left[\begin{array}{ccc}
k & k^{\prime} & K_{2} \\
q-q & 0
\end{array}\right] \mathcal{A}\left(K_{2}, K_{2}, 0, k, k^{\prime}\right)}{\sum_{k}(2 k+1)^{-1} \mathcal{A}(0,0,0, k, k)}
$$

is the asymmetry parameter of an angular distribution of emitted electromagnetic radiation. The angle $\theta$ is measured from the direction of projectile electron. The maximum value of $K$ is determined by values of the total angular momentum $J_{2}$ of an intermediate state of ion and the multipolarity $k$ of emitted radiation $K_{\max }=2 \min \left(J_{2}, k\right)$. In the case of dipole electric transitions, $K$ can be equal to 1 and 2 . The angular distribution of fluorescence radiation following the ionization of non-polarized atoms by non-polarized electrons was investigated by Berezhko et al. [12] using the density matrix approach.

\subsection{Angular correlations between fluorescence and escaping electron following the ionization of non-polarized atoms by non-polarized electrons}

In the case when polarization states of an ion $A^{+}$and emitted electrons are not registered, the cross-section for angular correlations between fluorescence and one of the escaping electrons is convenient to derive using expressions (14) and (15). Let us assume that the angular correlations are measured between a slower electron, which is marked by 2 , and a photon. The expression is as follows:

$$
\begin{aligned}
& \frac{\mathrm{d}^{3} \sigma\left(\alpha_{1} J_{1} \mathbf{p}_{0} \rightarrow \alpha_{2} J_{2} \mathbf{p}_{2} \rightarrow \alpha_{3} J_{3} \hat{\epsilon}_{q} \mathbf{k}_{0}\right)}{\mathrm{d} \varepsilon_{2} \mathrm{~d} \Omega_{2} \mathrm{~d} \Omega_{k_{0}}}=\frac{1}{2\left(2 J_{1}+1\right)} \\
& \times \int \mathrm{d} \Omega_{1} \frac{d^{4} \sigma\left(\alpha_{1} J_{1} \mathbf{p}_{0} \rightarrow \alpha_{2} J_{2} \mathbf{p}_{1} \mathbf{p}_{2} \rightarrow \alpha_{3} J_{3} \hat{\epsilon}_{q} \mathbf{k}_{0}\right)}{\mathrm{d} \varepsilon_{2} \mathrm{~d} \Omega_{1} \mathrm{~d} \Omega_{2} \mathrm{~d} \Omega_{k_{0}}}= \\
& \sum_{K_{2}, N_{2}} \frac{\mathrm{d}^{2} \sigma_{K_{2} N_{2}}^{\text {ion }}\left(\alpha_{1} J_{1} \mathbf{p}_{0} \rightarrow \alpha_{2} J_{2} \mathbf{p}_{2}\right)}{\mathrm{d} \varepsilon_{2} \mathrm{~d} \Omega_{2}} \frac{\mathrm{d} W_{K_{2} N_{2}}^{r}\left(\alpha_{2} J_{2} \rightarrow \alpha_{3} J_{3} \hat{\epsilon}_{q} \mathbf{k}_{0}\right)}{\mathrm{d} \Omega_{k_{0}}} .
\end{aligned}
$$


The expression for the first term in (25) is

$$
\begin{aligned}
& \frac{\mathrm{d}^{2} \sigma_{K_{2} N_{2}}^{\text {ion }}\left(\alpha_{1} J_{1} \mathbf{p}_{0} \rightarrow \alpha_{2} J_{2} \mathbf{p}_{2}\right)}{\mathrm{d} \varepsilon_{2} \mathrm{~d} \Omega_{2}}=\frac{(4 \pi)^{2} C_{2}\left[2 K_{2}+1\right]^{1 / 2}}{2\left(2 J_{1}+1\right)} \\
& \times \sum_{K_{\lambda_{0}}, K_{\lambda_{2}}} \mathcal{B}^{\text {ion }}\left(0, K_{\lambda_{0}}, K_{\lambda_{0}}, K_{\lambda_{0}}, 0, K_{\lambda_{2}}, K_{\lambda_{2}}, 0,0,0, K_{\lambda_{2}}, 0, K_{\lambda_{2}}\right) \\
& \times \sum_{N_{\lambda_{0}}, N_{\lambda_{2}}}\left[\begin{array}{l}
K_{2} K_{\lambda_{2}} K_{\lambda_{0}} \\
N_{2} N_{\lambda_{2}} N_{\lambda_{0}}
\end{array}\right] Y_{K_{\lambda_{0}} N_{\lambda_{0}}}^{*}\left(\hat{p}_{0}\right) Y_{K_{\lambda_{2}} N_{\lambda_{2}}}\left(\hat{p}_{2}\right),
\end{aligned}
$$

and that for the second term is (15). At $z$ axis along the direction of incoming electrons, one gets $N_{2}=-N_{\lambda_{2}}$, and

$$
\begin{aligned}
& \frac{\mathrm{d}^{2} \sigma_{K_{2} N_{2}}^{\text {ion }}\left(\alpha_{1} J_{1} \rightarrow \alpha_{2} J_{2} \mathbf{p}_{2}\right)}{\mathrm{d} \varepsilon_{2} \mathrm{~d} \Omega_{2}}=\frac{(4 \pi)^{3 / 2} C_{2}\left[2 K_{2}+1\right]^{1 / 2}}{2\left(2 J_{1}+1\right)} \sum_{K_{\lambda_{0}} K_{\lambda_{2}}}\left[2 K_{\lambda_{0}}+1\right]^{1 / 2} B^{\text {ion }}\left(K_{\lambda_{0}}, K_{\lambda_{2}}\right) \\
& \times\left[\begin{array}{cc}
K_{2} & K_{\lambda_{2}} \\
N_{2}-N_{2} & K_{\lambda_{0}}
\end{array}\right] Y_{K_{\lambda_{2}}-N_{2}}\left(\hat{p}_{2}\right) .
\end{aligned}
$$

Here

$$
B^{\text {ion }}\left(K_{\lambda_{0}}, K_{\lambda_{2}}\right)=\mathcal{B}^{\text {ion }}\left(0, K_{\lambda_{0}}, K_{\lambda_{0}}, K_{\lambda_{0}}, 0, K_{\lambda_{2}}, K_{\lambda_{2}}, 0,0,0, K_{\lambda_{2}}, 0, K_{\lambda_{2}}\right)
$$

\subsection{Magnetic dichroism in the angular distribution of fluorescence radiation following the ionization of polarized atoms by non-polarized electrons}

Magnetic dichroism is known as the dependence of intensity of fluorescence radiation following excitation, ionization, or photoionization of atoms on the direction of initial polarization of atoms. In the case of ionization of polarized atoms by non-polarized electrons, the cross-section for the process (1) suitable to describe the magnetic dichroism can be easily obtained by summing the general expression (2) over the magnetic components of nonregistered angular momenta $M_{3}, m_{1}, m_{2}$, averaging over $m_{0}$, and integrating over the angles of scattered and emitted electrons:

$$
\begin{aligned}
& \frac{\mathrm{d}^{2} \sigma\left(\alpha_{1} J_{1} M_{1} \mathbf{p}_{0} \rightarrow \alpha_{2} J_{2} \rightarrow \alpha_{3} J_{3} \hat{\epsilon}_{q} \mathbf{k}_{0}\right)}{\mathrm{d} \varepsilon_{2} \mathrm{~d} \Omega_{k_{0}}}= \\
& \times \frac{1}{2} \int \mathrm{d} \Omega_{1} \int \mathrm{d} \Omega_{2} \sum_{M_{3}, m_{0}, m_{1}, m_{2}} \frac{\mathrm{d}^{4} \sigma\left(\alpha_{1} J_{1} M_{1} \mathbf{p}_{0} m_{0} \rightarrow \alpha_{2} J_{2} \mathbf{p}_{1} m_{1} \mathbf{p}_{2} m_{2} \rightarrow \alpha_{3} J_{3} M_{3} \hat{\epsilon}_{q} \mathbf{k}_{0}\right)}{\mathrm{d} \varepsilon_{2} \mathrm{~d} \Omega_{1} \mathrm{~d} \Omega_{2} \mathrm{~d} \Omega_{k 0}}= \\
& \frac{1}{2} \sum_{K_{2}, N_{2}} \frac{\mathrm{d} \sigma_{K_{2} N_{2}}^{\text {ion }}\left(\alpha_{1} J_{1} M_{1} \mathbf{p}_{0} \rightarrow \alpha_{2} J_{2}\right)}{\mathrm{d} \varepsilon_{2}} \frac{\mathrm{d} W_{K_{2} N_{2}}^{r}\left(\alpha_{2} J_{2} \rightarrow \alpha_{3} J_{3} \hat{\epsilon}_{q} \mathbf{k}_{0}\right)}{\mathrm{d} \Omega_{k_{0}}},
\end{aligned}
$$

where $K_{s 0}=K_{s 1}=K_{s 2}=K_{2}^{\prime}=K_{1}^{\prime}=K^{\prime}=K_{\lambda_{1}}=K_{\lambda_{2}}=0, K_{\lambda_{0}}=K_{0}^{\prime}, K_{r}=K$, the laboratory $z$ axis coincides with the direction of incoming electrons $\left(N_{\lambda_{0}}=0\right)$, and

$$
\begin{aligned}
& \frac{\mathrm{d} \sigma_{K_{2} N_{2}}^{\text {ion }}\left(\alpha_{1} J_{1} M_{1} \mathbf{p}_{0} \rightarrow \alpha_{2} J_{2}\right)}{\mathrm{d} \varepsilon_{2}}=\int \mathrm{d} \Omega_{1} \int \mathrm{d} \Omega_{2} \sum_{m_{0}, m_{1}, m_{2}} \frac{\mathrm{d}^{3} \sigma\left(\alpha_{1} J_{1} M_{1} \mathbf{p}_{0} m_{0} \rightarrow \alpha_{2} J_{2} \mathbf{p}_{1} m_{1} \mathbf{p}_{2} m_{2}\right)}{\mathrm{d} \varepsilon_{2} \mathrm{~d} \Omega_{1} \mathrm{~d} \Omega_{2}}= \\
& \frac{C_{2}}{2}(4 \pi)^{2} \sum_{K_{2}, K_{\lambda_{0}}, K_{0}, N_{2}}\left[\left(2 K_{2}+1\right)\left(2 K_{\lambda_{0}}+1\right)\right]^{1 / 2} B\left(K_{0}, K_{\lambda_{0}}, K_{2}\right)\left[\begin{array}{ccc}
K_{0} K_{\lambda_{0}} K_{2} \\
N_{2} & 0 & N_{2}
\end{array}\right]
\end{aligned}
$$




$$
\times(-1)^{J_{1}-M_{1}}\left[\frac{4 \pi}{2 J_{1}+1}\right]^{1 / 2}\left[\begin{array}{ccc}
J_{1} & J_{1} & K_{0} \\
M_{1}-M_{1} & 0
\end{array}\right] Y_{K_{0} N_{2}}\left(\hat{J}_{1}\right) .
$$

Here

$$
B\left(K_{0}, K_{\lambda_{0}}, K_{2}\right)=\mathcal{B}^{\text {ion }}\left(K_{0}, K_{\lambda_{0}}, K_{2}, K_{\lambda_{0}}, 0, K_{2}, 0,0,0,0,0,0,0\right)
$$

The magnetic dichroism is the difference between the cross-sections (30) measured for the opposite directions of the total angular momentum $\mathbf{J}_{1}$. In the case of choosing the direction of $\mathbf{J}_{1}$ to be parallel and antiparallel to the $z$ axis which coincides with the direction of incoming electron, $Y_{K_{0} N_{2}}(0,0)=Y_{K_{0} N_{2}}(\pi, 0)=$ $\left[\left(2 K_{0}+1\right) / 4 \pi\right]^{1 / 2} \delta\left(N_{2}, 0\right)$, and the difference of the cross-sections (30) is equal to

$$
\begin{aligned}
& \Delta=\sum_{K_{2}} \frac{\mathrm{d} \sigma_{K_{2} 0}^{\text {ion }}\left(\alpha_{1} J_{1} M_{1}=J_{1} \rightarrow \alpha_{2} J_{2}\right)}{\mathrm{d} \varepsilon_{2}} \\
& \times \frac{\mathrm{d} W_{K_{2} 0}^{r}\left(\alpha_{2} J_{2} \rightarrow \alpha_{3} J_{3} \hat{\epsilon}_{q} \mathbf{k}_{0}\right)}{\mathrm{d} \Omega_{k_{0}}},
\end{aligned}
$$

where

$$
\begin{aligned}
& \frac{\mathrm{d} \sigma_{K_{2} 0}^{\text {ion }}\left(\alpha_{1} J_{1} M_{1}=J_{1} \rightarrow \alpha_{2} J_{2}\right)}{\mathrm{d} \varepsilon_{2}}=C_{2}(4 \pi)^{2} \\
& \times \sum_{K_{\lambda_{0}}, K_{0}}\left[\frac{\left(2 K_{\lambda_{0}}+1\right)\left(2 K_{2}+1\right)\left(2 K_{0}+1\right)}{2 J_{1}+1}\right]^{1 / 2} \\
& \times B\left(K_{0}, K_{\lambda_{0}}, K_{2}\right)\left[\begin{array}{ccc}
K_{0} & K_{\lambda_{0}} & K_{2} \\
0 & 0 & 0
\end{array}\right]\left[\begin{array}{ccc}
J_{1} & J_{1} & K_{0} \\
J_{1} & -J_{1} & 0
\end{array}\right] .
\end{aligned}
$$

Expression (32) can be integrated over the energies of emitted electrons:

$$
\begin{aligned}
& \Delta^{\prime}=\sum_{K_{2}} \sigma_{K_{2} 0}^{\text {ion }}\left(\alpha_{1} J_{1} M_{1}=J_{1} \rightarrow \alpha_{2} J_{2}\right) \\
& \times \frac{\mathrm{d} W_{K_{2} 0}^{r}\left(\alpha_{2} J_{2} \rightarrow \alpha_{3} J_{3} \hat{\epsilon}_{q} \mathbf{k}_{0}\right)}{\mathrm{d} \Omega_{k_{0}}}
\end{aligned}
$$

The Clebsch-Gordan coefficient in (33) is not equal to zero if $K_{0}+K_{\lambda_{0}}+K_{2}$ is an even number. Thus, having in mind that $K_{0} \leq 2 J_{1}$, one can expect a non-zero magnetic dichroism for $J_{1} \geq 1$ in the case of electric dipole radiation $\left(K_{2}=0,1,2\right)$.

Magnetic dichroism may reveal itself even in the measurement of the total cross-section, i.e. for the cross-section (29) integrated over the angles of emitted radiation $\left(K_{2}=0\right)$ :

$$
\Delta^{\prime \prime}=
$$

$$
\begin{aligned}
& \sigma_{00}^{\text {ion }}\left(\alpha_{1} J_{1} M_{1} \rightarrow \alpha_{2} J_{2}\right) W_{00}^{r}\left(\alpha_{2} J_{2} \rightarrow \alpha_{3} J_{3}\right)= \\
& \frac{1}{(4 \pi)^{3}} \sigma^{\text {ion }}\left(\alpha_{1} J_{1} M_{1} \rightarrow \alpha_{2} J_{2}\right) W^{r}\left(\alpha_{2} J_{2} \rightarrow \alpha_{3} J_{3}\right) .
\end{aligned}
$$

Here one can see that the magnetic dichroism depends only on the first process.

\section{Concluding remarks}

In two-step approximation, the general expression for the cross-section describing the properties of fluorescence radiation emitted following the ionization of polarized atoms by polarized electrons is obtained. The expression describes the polarization states and angular distributions of all particles both in the initial and final states. Some special cases suitable for the specific experimental conditions are studied as more simple cases of the general expression. In the case of ionization of non-polarized atoms by non-polarized electrons, the expressions for the parameters of the asymmetry in the angular distribution of fluorescence as well as angular correlations between fluorescence photon and one of emitted electrons are presented. The magnetic dichroism in the angular distribution of fluorescence radiation is also studied.

\section{Acknowledgements}

The study was partially funded by the Joint TaiwanBaltic Research project and the Ministry of Education and Science of Republic of Lithuania, Contract No. SUT-683.

\section{References}

[1] S.C. McFarlane, The polarization of characteristic x radiation excited by electron impact, J. Phys. B 5, 19081915 (1972).

[2] A. Boileau, M. von Hellermann, W. Mandl, H.P. Summers, H. Weisen, and A. Zinoviev, Observation of motional Stark features in the Balmer spectrum of deuterium in the JET plasma, J. Phys. B 22, L145-L152 (1989). 
[3] W. Mandl, R.C. Wolf, M. von Hellermann, and H.P. Summers, Beam emission spectroscopy as a comprehensive plasma diagnostic tool, Plasma Phys. Controlled Fusion 35, 1373-1394 (1993).

[4] V.V. Balashov, A.N. Grum-Grzhimailo, and N.M. Kabachnik, Polarization and Correlation Phenomena in Atomic Collisions. A Practical Theory Course (Kluwer, New York, 2000).

[5] K.-N. Huang, Symmetries and polarization correlations in collision process, J. Phys. Conf. Ser. 80, 012007(29) (2007).

[6] F. Da Pieve, S. Di Matteo, D. Sébilleau, R. Gunnella, G. Stefani, and C.R. Natoli, Angular correlation between photoelectrons and Auger electrons within scattering theory, Phys. Rev. A 75, 052704 (2007).

[7] A. Kupliauskienè, N. Rakštikas, and V. Tutlys, General expression of the photoionization cross section of an atom in polarized $L S$ state, Lithuanian J. Phys. 40, 311-320 (2000).

[8] A. Kupliauskienė, N. Rakštikas, and V. Tutlys, Polarization studies in the photoionization of atoms using a graphical technique, J. Phys. B 34, 1783-1803 (2001).

[9] A. Kupliauskienè and K. Glemža, General expression for ionization cross-section of polarized atoms by polarized electrons, Lithuanian J. Phys. 43, 89-97 (2003).

[10] A. Kupliauskienè, Atomic theory methods for the polarization of photon and electron interactions with atoms, Lithuanian J. Phys., 44, 199-218 (2004).

[11] A. Kupliauskienè, Photoexcitation of polarized atoms by polarized radiation, Lithuanian J. Phys. 44, 17-26 (2004).

[12] E.G. Berezhko, N.M. Kabachnik, and V.V. Sizov, The theory of coincidence experiments on electron impact ionization of inner atomic shells, J. Phys. B 11, 18191832 (1978).

[13] R.K. Singh and R. Shanker, Polarization of argon $K$ $\mathrm{x}$ radiation following electron-impact ionization, Phys. Rev. A 67, 012708 (2003).

[14] A. Kupliauskienè, Investigation of fluorescence radiation following radiative recombination of ions and electrons, Nucl. Instrum. Methods B 235, 252-256 (2005).

[15] Z. Rudzikas, Theoretical Atomic Spectroscopy (Cambridge University Press, Cambridge, 2007).

[16] A.P. Jucys and A.A. Bandzaitis, Theory of Angular Momentum in Quantum Mechanics (Mintis, Vilnius, 1965) [in Russian].

\title{
POLIARIZUOTAIS ELEKTRONAIS JONIZUOTU POLIARIZUOTŲ ATOMŲ FLUORESCENCIJA
}

\author{
A. Kupliauskiené ${ }^{a}$, K. Glemža ${ }^{b}$, K.-N. Huang ${ }^{c}$ \\ ${ }^{a}$ VU Teorinès fizikos ir astronomijos institutas, Vilnius, Lietuva \\ ${ }^{\mathrm{b}}$ Vilniaus universitetas, Vilnius, Lietuva \\ ${ }^{\mathrm{c}}$ Kinijos akademijos Atomu ir molekuliu mokslu institutas, Taipejus, Taivanis
}

\section{Santrauka}

Atomų ir jonų jonizacija elektronais - vienas svarbiausių vyksmų laboratorineje ir astrofizikinejje plazmoje. Tiriant tokiu vyksmu metu atsiradusių jonų būsenų suirimo produktus, galima gauti daug naudingos informacijos ne tik apie atomo sandarą, bet ir apie atomo ar jono sužadintas būsenas sukūrusius procesus ir daugiadaleles sąveikas. Sužadinta būsena po vidinio sluoksnio jonizacijos suyra, atomui išspinduliuojant fotoną (fluorescencijos vyksmas). Elektronais jonizuotu atomų fluorescencija nagrinejjama kaip sudètingas procesas dviejų stadijų (etapu) artinyje. Naudojant atomo teorijos metodus ir judejjimo kiekio momento grafinius metodus sutrikdytujų bangu artinyje, surasta diferencialinio skerspjūvio (tikimy- bès) bendroji išraiška, aprašanti visu procese dalyvaujančiu dalelių poliarizacija pradinejje ir galinejje būsenose, atplèštu elektronų ir fluorescencijos kampinius pasiskirstymus bei jų tarpusavio kampines koreliacijas. Ji panaudota surasti paprastesnemms diferencialinio skerspjūvio išraiškoms, kurios reikalingos ịvairiems eksperimente matuojamiems dydžiams apskaičiuoti. Pateiktos elektromagnetinès spinduliuotès kampini pasiskirstymą, kampines koreliacijas tarp fluorescencijos spinduliuotès ir atplèštojo elektrono, fluorescencijos magnetini dichroizmą, jonizuojant nepoliarizuotus ir poliarizuotus atomus nepoliarizuotais elektronais, nusakančios formulès. 